\title{
Analisis Resiko Kecelakaan Kerja Menggunakan Metode HIRARC PT. SPI
}

\author{
Abdul Wahid ${ }^{1}$, Misbah Munir ${ }^{2}$, Achmad Rofiq Hidayatulloh ${ }^{3}$ \\ ${ }^{123} J u r u s a n$ Teknik Industri, Universitas Yudharta Pasuruan \\ *Koresponden Penulis, E-mail: wahid@yudharta.ac.id
}

\author{
Diterima : 16 September 2020 \\ Direvisi : 16 November 2020 \\ Disetujui : 24 November 2020
}

\begin{abstract}
Abstrak
PT.SP Imerupakan sebuah perusahaan yang memproduksi material sandwich panel. Para kontraktor, dan para penggiat infrastruktur lainnya cukup menikmati penggunaannya pada saat ini, dikarenakan dapat menghasilkan banyak keuntungan. Namun, PT.SPI, pekerjaan masih banyak dilakukan secara konvenional. Penggunaan manajemen K3 sangat berpengaruh terhadap penelitian ini. Dalam mencegah terjadinya kecelakaan kerja dalam aktivitas pada perusahaan yang mengakibatkan cacat fisik pada pekerja bisa di tanggulangi dengan K3. Metode HIRARC merupakan manajemen resiko dan yang menentukan arah penerapan K3 dalam perusahaan. Hasil penelitian yang dilakukan menghasilkan bahwa metode HIRARC ini, dapat menganalisis resiko keselamatan kerja dalam mengetahui tingkat resiko keselamatan kerja di PT.SPI. Penelitian menunjukkan bahwa sikap pekerja sangat berpengaruh terhadap penerapan kesehatan dan keselamatan kerja pada saat terjadinya kecelakaan kerja. Kesehatan dan Keselamatan Kerja dalam bekerja digunakan untuk melindungi dan menjamin keselamatan dan kesehatan tenaga kerja, meminimalisir kemungkinan terjadinya kecelakaan kerja, dan meningkatkan kesejahteraan pekerja. Kemudian faktor yang berpengaruh terhadap risiko keselamatan dan kesehatan kerja yaitu: faktor manusia, faktor standarisasi, faktor lingkungan kerja, faktor sarana prasarana yang meliputi alat pelindung diri, dan faktor cuaca. Saran dari penelitian ini adalah perusahaan segera mewujudkan Kebijakan atau Standart Operasional Prosedur (SOP), memperhatikan faktor penyebab kecelakaan kerja, dan menambahkan variabel produktivitas untuk penelitian selanjutnya.
\end{abstract}

Kata Kunci: HIRARC, Manajemen Keselamatan dan Kesehatan Kerja, Sandwich Panel

\section{Pendahuluan}

Semua karyawan memerlukan pemahaman dasar tentang risiko jika budaya keselamatan organisasi ingin dipertahankan [1].Pola pikir menjadi salah satu alteratif dalam sebuah kegiatan manusia. Hal ini disebabkan oleh kebutuhan manusia yang terus meningkat akan kemudahan teknologi yang ada, di tekankan pada usaha manufaktur. Pemakaian objek "Sandwich Panel" para kontraktor lebih berminat lantaran banyaknya keuntungan yang cukup besar. Pada beberapa proses pengerjaan bangunan, sandwich panel ini digunakan sebagai partisi dinding serta plafond untuk bagian tertentu. Dalam proses produksi di perusahaan tersebut masih ada beberapa pekerjaan yang masih manual dalam proses pengerjaannya. Yang mungkin saja dalam pekerjaan mampu mengakibatkan terjadinya resiko kecelakaan kerja [1]. Tingginya angka kecelakaan kerja dapat juga dipastikan karena kecerobohan atau karena kurangnya penerapan dalam keselamatan dalam bekerja. Organisasi internasional menunjukkan ketertarikan yang kuat untuk melaksanakan risiko proses manajemen pengambilan keputusan untuk pencegahan kecelakaan Sehingga dapat meminimalisir kecelakaan pada pekerja [2]. Agar tidak terjadi kerugian pada pekerja maupun perusahaan maka sistem keselamatan bagi pekerja harus diterapkan. OHSAS 18001:2007 telah menerapkan sistem K3 secara baik sampai internasional. Dalam peraturan yang tertera pada OHSAS 18001 manajemen K3 merupakan sebuah upaya untuk mencegah terjadinya resiko yang ada dalam aktivitas perusahaan yang dapat mengakibatkan cidera pada manusia, kerusakan atau gangguan terhadap perusahaan. Hazard Identification, Risk Assessment dan Risk Control merupakan manajemen resiko bisa digunakan [3][4]. Pencegahan yang efektif dalam mencegah kecelakaan dan efek lain yang merugikan sangat bisa menggunakan sistem manajemen Resiko. Upaya pelaksanaan K3 secara baik dan harus sesuai dengan undangundang ketenagakerjaan guna meminimalisir kecelakaan yang terjadi di tempat kerja. Terdapat kesalahan yang menyebabkan kerugian bagi perusahaan juga disebabkan faktor tenaga kerja itu sendiri, maupun orang lain. Keselamatan dan Kesehatan Kerja merupakan 
hal yang tidak bisa di pandang sebelah mata dalam sebuah aktifitas pekerjaan segala hal karena sangat berhadapan langsung dengan nyawa pekerja [5].

Di Indonesia telah ditetapkan Undang-Undang No. 1 Tahun 1970 terkait Keselamatan Kerja, Peraturan Menteri No. PER- 05/MEN/1996 tentang Sistem Manajemen Keselamatan dan Kesehatan Kerja. Tujuan dari peraturan-peraturan tersebut mengantisipasi dan mencegah terjadinya resiko kecelakaan kerja [7][8].

Fasilitas-fasilitas yang melengkapi para pekerja juga hal yang sangat penting dalam keberlangsungan keselamatan kerja [9]. Kenyataan dilapangan ada beberapa pekerja yang bandel dan kurang peduli terhadap penerapan kesehatan dan keselamatan kerja yang berpotensi menimbulkan kecelakaan terutama pada pekerja lapangan. Sistem Manajemen Resiko Keselamatan dan Kesehatan Kerja di perusahaan terkait akan hancur kalau tidak bisa diterapkan. Sistem pengawasans ecara kontinyu dan ketat dapat mengurangi pelanggaran yang merugikan perusahaan dan pekerja. Kesadaran dan pemahaman mengenai pentingnya K3 harus selalu di dengungkan, serta dibiasakan di seluruh para pekerja. Pemahaman dan pelaksanaan K3 di perusahaan sangat diperlukan, terutama dalam syarat - sayarat kerja. Infornasi terkait keselamatan kerja perlu disosialisasikan guna lebih memahamankan pentingnya K3 dalam bekerja dengan baik dan benar. Dengan demikian diperlukan analisis ini guna mengetahui tingkat resiko keselamatan kerja dengan metode HIRARC (Hazard Identification, Risk Assessment and Risk Control) di PT.SPI [10].

\section{Tinjauan Pustaka}

\subsection{HIRARC (Hazard Identification, Risk Assessment and Risk Control)}

HIRARC (Hazard Identification, Risk Assessment and Risk Control) kegiatan proses identifikasi bahaya dalam aktifitas rutin ataupun non rutin diperusahaan, kemudian tujuan mencegah terjadi kecelakaan kerja dengan meminimalisir terjadinya kecelakaan kerja. Aplikasi K3 bisa berjjalan dengan baik bisa dilakukan dengan perencanaan yang baik diantaranya, identifikasi bahaya, peniliaian dan pengendalian risiko semua itu yang ada di dalam manajemen risiko. Variabel - variable resiko akan di dapatkan dengan menggunakan metode HIRARC setelah itu penilaian risiko dan pengendalian risiko dapat dilakukan guna mengurangi paparan bahaya yang terdapat pada setiap jenis pekerjaan [9][3].

\subsection{Keselamatan dan Kesehatan Kerja}

Menurut ILO/WHO (1998) Keselamatan dan Kesehatan Kerja (K3) adalah suatu upaya promosi, perlindungan dan peningkatan derajat kesehatan yang setinggi-tingginya mencakup aspek fisik, mental, dan sosial untuk kesejahteraan seluruh pekerja di semua tempat kerja [5]. Tempat kerja yang aman dan nyaman dapat terwujud jika ada jaminan keselamatan dan kesehatan kerja. Dengan adanya keselamatan dan kesehatan kerja dapat mempengaruhi prestasi kerja karyawan [6].

Pelaksanaan K3 merupakan salah satu bentuk upaya untuk menciptakan tempat kerja yang sama, sehat, bebas dari pencemaran lingkungan, sehingga dapat mengurangi dan atau bebas dari kecelakaan kerja dan penyakit akibat kerja yang pada akhirnya dapat meningkatkan efisiensi dan produktivitas kerja. Keselamatan dan Kesehatan Kerja (K3) merupakan salah satu upaya atau bentuk usaha yang harus dilakukan para pekerja dalam melakukan pekerjaan baik yang berasal dari individu sendiri atau lingkungan kerja untuk memperoleh jaminan atas Keselamatan dan Kesehatan Kerja (K3) yang bertujuan agar pekerjaan yang dilakukan tersebut tidak mengancam dan membahayakan dirinya. Selanjutnya, pelaksanaan K3 merupakan suatu bentuk upaya untuk menciptakan tempat kerja yang aman, sehat, bebas dari pencemaran lingkungan, sehingga dapat mengurangi dan atau bebas dari kecelakaan kerja dan penyakit akibat kerja yang pada akhirnya dapat meningkatkan efisiensi dan produktivitas kerja[11].

\subsection{Kecelakaan Akibat Kerja}

kecelakaan adalah sebuah kejadian yang bisa jadi di luar pemikiran secara tiba-tiba dan tidak diharapkan. kesengajaan atau unsur perencanaan adalah hal perlu diperhatikandalam sebuah peristiwa kecelakaan disertai kerugian materil ataupun menimbulkan penderitaan dari skala paling ringan sampai skala paling berat [12]. Kecelakaan 
akibat kerja adalah bisa jadi di mulai dari berangkat kerja sampai menuju tempatkerja atau kecelakaan kerja terjadi pada lingkup kerja. Menurut Bird and Germain, FJ (1990) kecelakaan kerja adalah kejadian tidak diharapkan yang mengakibatkan kesakitan (cedera atau korban jiwa) pada orang, kerusakan pada properti dan kerugian dalam proses yang terjadi saat pekerjaan dilakukan. Karakteristik Kecelakaan kerja bisa di identifikasi baik dengan bahan atau sumber energi (bahan kimia, suhu tinggi, kebisingan, mesin, listrik, dan lain lain) di atas nilai maksimal kemampuan tubuh manusia untuk mampu melakukannya yang menyebabkan teriris, terbakar, tertusuj, patah tulang, dan bisa terjadi pada organ tubuh yang lain [9].

\section{Metode Penelitian}

Pendekatan kualitatif di perlukan dalam penelitian ini dengan studi evaluasi yang diperuntukkan untuk mendapatkan informasi mengenai resiko keselamatan pekerja yang bekerja pada PT.SPI setelah itu hasil observasi dibandingkan oleh peneliti untuk menentukan tingkat resiko keselamatan kerja, dalam mengidentifikasi resiko maka di gunakan dengan metode HIRARC, cara menilai resiko hingga pengendalian resiko dapat di lihat pada gambar.1.

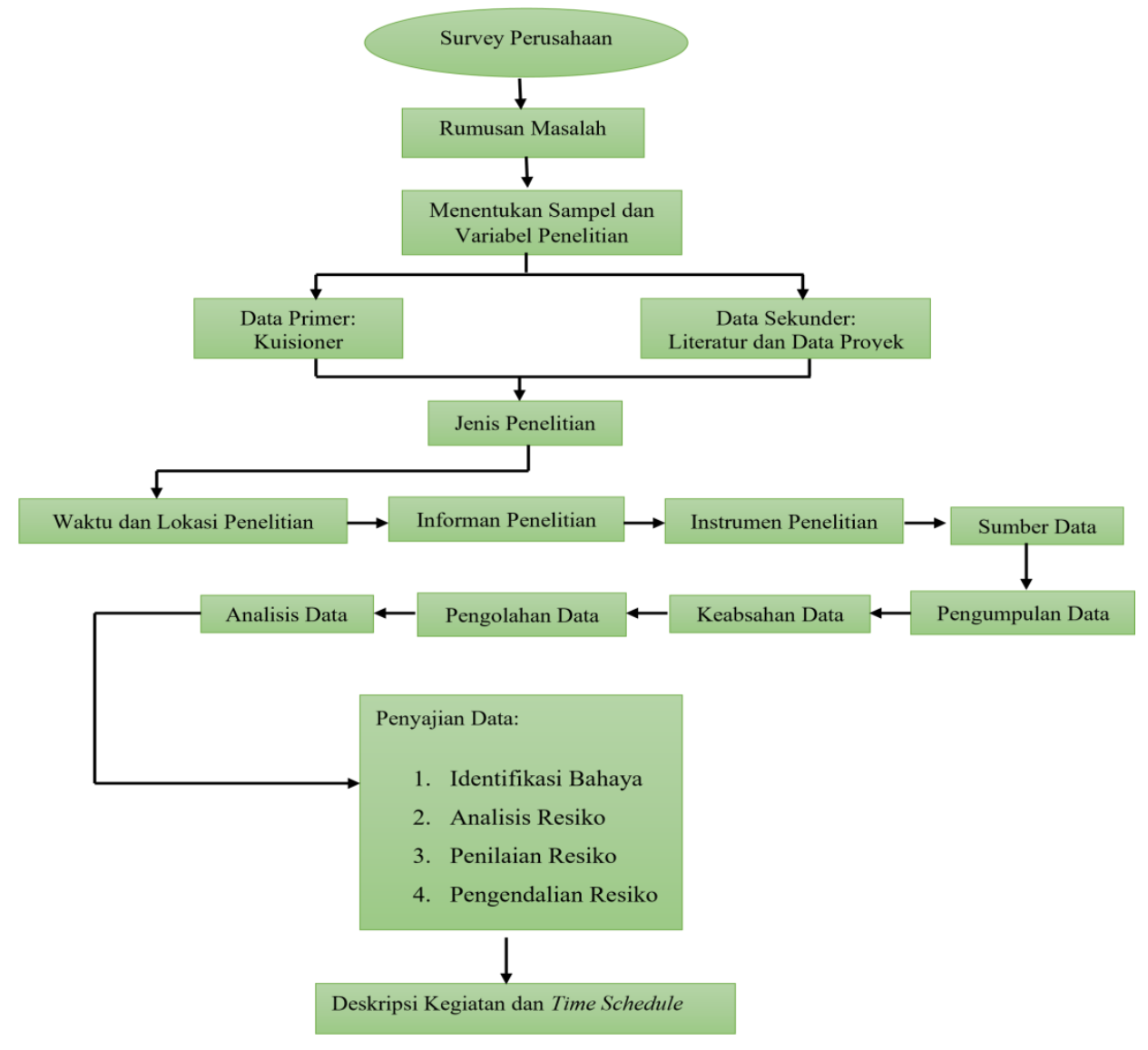

Gambar 1. Diagram Alir Penelitian

\section{Hasil dan Pembahasan}

\subsection{Program Kesehatan dan Keselamatan Kerja (K3)}

Program Kesehatan dan Keselamatan Kerja (K3) Berdasarkan hasil penelitian yang telah dilakukan pada perusahaan PT.SPI, program kesehatan dan keselamatan kerja sudah berjalan. Program kesehatan dan keselamatan kerja (K3) yang ada pada perusahaan meliputi pelatihan keselamatan, kontrol lingkungan kerja, pengawasan dan disiplin, publikasi keselamatan kerja, serta peningkatan kesadaran kesehatan dan keselamatan kerja (K3). Tujuan dari adanya program kesehatan dan keselamatan kerja (K3) sebagai pelatihan keselamatan yang dapat memberikan ilmu pengetahuan kepada seluruh karyawan yang 
bekerja di PT.SPI agar ketika bekerja mampu dan terlebih lagi menguasai dan memahami pekerjaan yang akan dikerjakan dan terhindar dari kejadian yang tidak diinginkan. Misalnya kecelakaan kerja yang akan merugikan karyawan maupun pihak perusahaan sendiri. Selain itu, karyawan diberikan pelatihan dan pemahaman secara menyeluruh terkait keselamatan dan kesehatan kerja dengan harapan program tersebut bisaa berjalan dengan baik dan mampu menekan resiko kecelakaan kerja [13].

Penerapan simbol atau atribut di PT.SPI meliputi pemasangan rambu-rambu bahaya pekerjaan, cara pemakaian alat pelindung diri yang terpampang di setiap sudut ruang kerja, bahaya merokok, cara menggunakan peralatan yang benar dan aman, serta terdapat pesanpesan keselamatan pada setiap ruang kerja yang dimaksudkan untuk diperhatikan oleh karyawan saat bekerja. Karyawan akan mengetahui secara langsung dampak dari melalaikan aturan terkait keselamatan kerja. Atasan berperan penting terhadap eberlangsungan kegiatan bawahannya, secara dengan mata telanjang dapat melihat kinerja tenaga kerjanya. Dilapangan apabila suatuhal semisal karyawan tidak memenuhi protokol standarisasi keselamatan dan hasil yang dihasilkan tidak memuaskan, secara otomatis karyawan tersebut akan diberikan teguran. Kemudian karyawan tersebut akan mendapatkan sanksi yang mana aada 3 sanksi yaitu Surat Peringatan 1 (SP1), Surat Peringatan 2 (SP2), Surat Peringatan 3 (S3). Otimalisasi kesadaran terkait kesehatan yang terdapat di perusahaan dimulai pada tingkatan yang rendah sampai pada tingkatan yang paling tinggi [9].

Pertama di berlakukan pada tingkatan yang paling rendah yaitu pada personal masingmasingseperti menggunakan APD dan lain-lain, setelah itu menuju tingkat keselatan yang lebih tinggi yang lebih kearah makro dimana nantinya hasil dari masukan-masukan sebagai media aturan yang ada di perusahaan tersebut.audit lingkungan kerja lebih baik dilakukan oleh atasan langsung sehinggan akan meenghasilkan suasana yang kondusif terlebih sering diklakukan secara berkala [12][4]. Beberapa hal yang harus sering dilakukan pengecekan terkait alat pelindung dirir seperti masker, katelpak, helm, kacamata, sarung tangan, sepatu safty dan lain-lain. Maksud dari hal tersebut adalah apabila ada stok alat pelindung diri mulai meenipis maka bisa dengan cepat di ambil tindakan untuk dilakukan pemesaanan kembali. Perusahaan tidak pernah mengagendakan kegiatan rutinitas secara berkala terkait olahraga sehingga di sini juga memiliki dampak terhadap kesehatan karyawan, akan tetapi kegiatan tersebut dilakukan secara individu oleh karyawan disela-sela liburan kerja, pengecekan kesehatan tidak pernah dilakukan oleh perusahaan terkecuali apabila ada momen-momen tertentu seperti ada permintaan dari karyawan [7].

\subsection{Faktor - faktor Penyebab Terjadinya Risiko Kecelakaan Kerja}

\section{A. Faktor Mesin}

Dengan mesin, produksi dan produktifitas bisa ditingkatkan, sehingga di perlukan pengendalian dan penggontrolan secara berkala terkait kondisi mesin, sehinggga dengan kondisi mesin tidak stabil maka akan memiliki resiko kecelakaan kerja yang cukup tinggi.

B. Faktor Manusia (Human Error)

1. Ketidaktahuan dalam menjalankan material, dan peralatan teknisi harus lebih memahami dengan karakteristik mesin yang di operasionalkan. Bila teknisitidak mampu menguasai mesin tersebut maka akan memicu terjadinya kecelakaan dalam bekerja. Pengetahuan dari teknisi dalam pemasangan material atau penggunaan peralatan kerja, memahami karakter dari material, dan lain sebagainya. Hal tersebut, jadi sangat penting, bila hal tersebut hanya sembarangan, maka juga akan membahayakan kualitas material, peralatan dan manusia itu sendiri.

2. Kurangnya disiplin oleh karyawan tersebut juga akan membahayakan terhadap diri sendiri dan juga bisa membahayakan kepada orang lain.

C. Standarisasi

1. Belum adanya peraturan atau standarisasi yang membahas mengenai setiap pekerjaan pemasangan panel dan pengelolahan panel. 
2. Banyaknya pekerja yang tidak memperhatikan intruksi keselamatan dan kesehatan kerja dan risiko yang kemungkinan terjadi.

3. Kurang pengetahuan mengenai bahaya yang ada disekitar maupun yang lagi di kerjakan

D. Lingkungan Kerja

1. Panel adalah bahan baku bangunan yang berat dan sisi lebar panel karena sisa potongan pelat yang masih tajam

2. Saat bongkar barang yang tidak safety, terburu-buru, tidak sesuai prioritas yang dikerjakan

3. Pemotongan panel, aluminium dan aksesoris lain tidak pada tempat yang sesuai

4. Penempatan mastic sealant dan silicon yang kurang benar menyebabkan udara disekitar lingkungan kerja terkontaminasi

5. Kelengkapan alat pelindung diri yang kurang memadai sehingga pekerja harus extra hati-hati

6. Kebisingan mesin continous, boiler dan dust collector yang sedang beroperasi menyebabkan pendengaran pekerja terganggu

7. Kerusuhan warga sekitar yang beberapa kali melempar batu, botol kaca dari luar pagar pabrik

8. Adanya bahan kimia berbahaya yaitu ISO, POLY, Cyclopentane dan Catalist yang mudah meledak, terbakar dan radiasi.

9. Bahan kimiaberbahaya bisa menyebabkan iritasi terkena mata atau kulit secara langsung

10. Gangguan pernafasan karena partikel PU yang terhirup, sesak nafas, kesehatan yang terganggu dalam jangka panjang

11. Kemungkinan risiko yang bisa terjadi saat proses pembangunan yang di sebabkan oleh panel yaitu patah tulang, tertimpah lembaran panel saat pengangkatan maupun pemasangan, luka berdarah karena pelat yang tajam, iritasi mata saat pemotongan panel, kaki dan tangan sering tergores sampai dalam sampai perlu dijahit.

E. Insiden Kecelakaan Kerja

Insiden kecelakaan kerja yang pernah terjadi ini didapat dari infomasi informen terpercaya. Data yang diambil dalam kurung waktu 3 bulan di PT.SPI.

Tabel 1. Data Kecelakaan Kerja Tahun 2019

\begin{tabular}{|c|l|c|c|c|}
\hline \multirow{2}{*}{ No } & \multirow{2}{*}{ Kasus kejadian kecelakaan } & \multicolumn{3}{|c|}{ Periode } \\
\cline { 3 - 5 } & Tergores Plat & 4 & - & 2 \\
\hline 2 & Tertimpa Barang & - & 2 & 1 \\
\hline 3 & Terkena Chemical & 1 & 3 & 1 \\
\hline 4 & Terpleset & 1 & - & 1 \\
\hline 5 & Jatuh dari ketinggian & 2 & - & - \\
\hline 6 & Terkena percikan las & - & 1 & - \\
\hline 7 & Tergores mesin pemotong & 1 & - & - \\
\hline
\end{tabular}

Sumber : Internal Perusahaan 


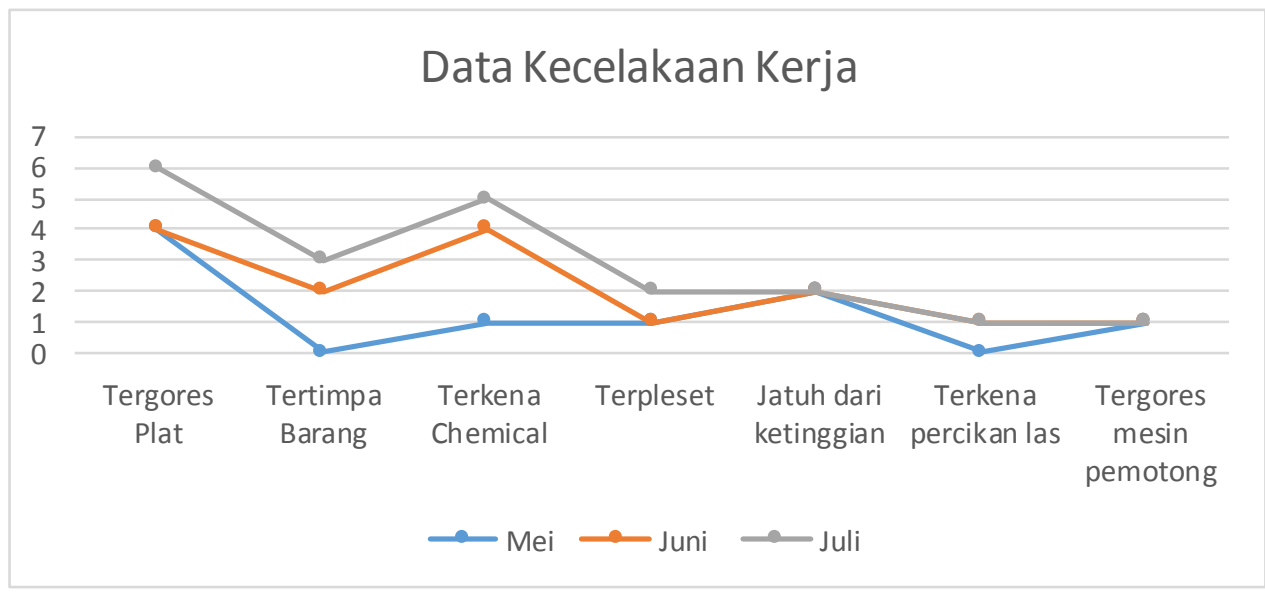

Gambar 1. Diagram Data Kecelakaan Kerja

\subsection{Hasil Identifikasi HIRARC pada PT.SPI}

Hasil identifikasi pada PT.SPI terdapat hasil bahwa tingkat resiko yang terjadi masih tergolong cukup tinggi dan sehingga dalam hal ini dapat diidentifikasi daan dapat diketahui bahwasannya system yang ada di perushaan ini daapat diartikan dan menunjukkan bahwa manajemen keselamatan dan kesehatan kerja yang terjadi saat ini masih belum di lakukan secara maksimal. Berikut hasil HIRARC yang ada pada PT.SPI dapat dilihat pada tabel 2:

Tabel 2. Perhitungan HIRARC

\begin{tabular}{|c|c|c|c|c|c|c|c|}
\hline $\begin{array}{l}\text { Nama } \\
\text { Kegiatan }\end{array}$ & Jenis Kecelakaan Kerja & $\begin{array}{l}\text { Penyebab } \\
\text { Kecelakaan }\end{array}$ & $\begin{array}{l}\text { Resiko atau } \\
\text { Dampak }\end{array}$ & $\begin{array}{l}\text { Kemung } \\
\text { kinan }\end{array}$ & $\begin{array}{c}\text { Konsek } \\
\text { uensi }\end{array}$ & WRAC & $\begin{array}{l}\text { Tingkat } \\
\text { Resiko }\end{array}$ \\
\hline Produksi & Terjatuh & Lingkungan Kerja & Regang Otot / Urat & 4 & 3 & 12 & Bersyarat \\
\hline Produksi & $\begin{array}{l}\text { Kontak Dengan Bahan- } \\
\text { Bahan Berhaya Atau } \\
\text { Radiasi }\end{array}$ & $\begin{array}{l}\text { Bahan-Bahan Atau } \\
\text { Zat-Zat Radiasi }\end{array}$ & Luka Dipermukaan & 5 & 4 & 23 & Tinggi \\
\hline Produksi & $\begin{array}{l}\text { Terbentur (Tergores, } \\
\text { Terpotong, Tertusuk) }\end{array}$ & Lingkungan Kerja & Luka Dipermukaan & 5 & 3 & 18 & Ketat \\
\hline Produksi & $\begin{array}{l}\text { Gerakan-Gerakan } \\
\text { Melebihi Kemampuan }\end{array}$ & Lingkungan Kerja & Tergores & 5 & 2 & 12 & Bersyarat \\
\hline Delivery & Tertimpa Benda & Lingkungan Kerja & $\begin{array}{l}\text { Memar Dan Luka } \\
\text { Dalam Lainya }\end{array}$ & 5 & 2 & 5 & Rendah \\
\hline Produksi & Tertimpa Benda & $\begin{array}{l}\text { Bahan-Bahan Atau } \\
\text { Zat-Zat Radiasi }\end{array}$ & $\begin{array}{l}\text { Memar Dan Luka } \\
\text { Dalam Lainya }\end{array}$ & 5 & 2 & 20 & Ketat \\
\hline Produksi & Terjepit Oleh Benda & Mesin & Regang Otot / Urat & 2 & 3 & 12 & Bersyarat \\
\hline Produksi & $\begin{array}{l}\text { Kontak Dengan Bahan- } \\
\text { Bahan Berhaya Atau } \\
\text { Radiasi }\end{array}$ & Mesin & Luka Di Permukaan & 1 & 3 & 18 & Ketat \\
\hline $\begin{array}{l}\text { Maintena } \\
\text { nce }\end{array}$ & Terjepit Oleh Benda & Mesin & Luka Dipermukaan & 1 & 3 & 7 & Rendah \\
\hline Delivery & $\begin{array}{l}\text { Terbentur (Tergores, } \\
\text { Terpotong, Tertusuk) }\end{array}$ & $\begin{array}{l}\text { Alat Angkut / Alat } \\
\text { Angkat }\end{array}$ & Luka Dipermukaan & 5 & 4 & 22 & Ketat \\
\hline
\end{tabular}




\begin{tabular}{|l|l|l|l|c|c|c|c|}
\hline Produksi & $\begin{array}{l}\text { Terbentur (Tergores, } \\
\text { Terpotong, Tertusuk) }\end{array}$ & Mesin & $\begin{array}{l}\text { Memar Dan Luka } \\
\text { Dalam Lainya }\end{array}$ & 5 & 3 & 15 & Bersyarat \\
\hline $\begin{array}{l}\text { Maintena } \\
\text { nce }\end{array}$ & Terkena Arus Listrik & Peralatan Listrik & Luka Luar & 1 & 4 & 23 & Tinggi \\
\hline $\begin{array}{l}\text { Maintena } \\
\text { nce }\end{array}$ & Pengaruh Suhu Tinggi & Peralatan Listrik & Regang Otot / Urat & 1 & 3 & 23 & Tinggi \\
\hline
\end{tabular}

Faktor yang berpengaruh terhadap risiko keselamatan dan kesehatan kerja yaitu :

a. Faktor manusia karena ketidaktahuan dan kecerobahan menggunakan peralatan kerja

b. Faktor Standarisasi yang belum ada dan tidak memperhatikan intruksi kerja dari pengawas mengenai keselamatan dan kesehatan kerja maupun risiko - risiko yang ada

c. Faktor Lingkungan kerja mengenai penempatan material yang tidak sesuai seperti drum/IBC tank bahan kimia,mastic silicont sealant

d. Faktor sarana prasarana yang meliputi alat pelindung diri yang kurang memadai seperti kacamata \& sarung tangan

e. Faktor cuaca dimana setiap tenisi harus memahani kondisi cuaca guna mengetahui sistem K3 yang harusnya diterapkan atau sesuai kondisi lapangan.

Penerapan manajemen risiko dipengaruhi oleh kondisi lingkungan kerja yang merupakan sikap pekerja, alat pelindung diri dan aturan-aturan yang di standarisasikan, berikut kejelasannya:

a) Sikap pekerja yang negatif berpengaruh terhadap kecelakaan keselamatan dan kesehatan kerja pada PT. SPI di Kabupaten Pasuruan. Artinya, semakin rendah sikap pekerja terhadap risiko - risiko maka semakin tinggi kecelakaan kerja yang terjadi.

b) Alat pelindung diri tidak begitu berpengaruh terhadap risiko kecelakaan kerja pada PT Starr Panel Industri karena alat perlindung diri tersedia namun tidak diperhatikan kelayakannya atau kurang memadai sehingga masih tingginya kecelakaan kerja.

c) Peraturan standarisasi sangat berpengaruh terhadap risiko kecelakaan kerja pada PT. SPI karena kurang kepedulian karyawan terhadap SOP K3 yang berlaku.

d) Pengawasan keselamatan dan kesehatan kerja tidak begitu berpengaruh terhadap risiko kecelakaan kerja pada PT. SPI karena banyak pekerja yang tidak memperhatikan aturan yang yang telah ada atau instruksi kerja.

\section{Penutup}

Berdasarkan hasil penelitian yang telah dilakukan untuk menguji Pengaruh Kesehatan Dan Keselamatan Kerja Terhadap Kinerja Karyawan Pada PT. SPI di Kabupaten Pasuruan, dapat disimpulkan bahwa:

Sikap pekerja yang negatif berpengaruh terhadap kecelakaan keselamatan dan kesehatan kerja pada PT. SPI di Kabupaten Pasuruan. Artinya, semakin rendah sikap pekerja terhadap risiko - risiko maka semakin tinggi kecelakaan kerja yang terjadi.

Didapatkan data bahwa SOP sangat berpengaruh terhadap resiko kecelakaan kerja yang ada diperusahaan dan diperlukan peninngkatan pengawasan terhadap tenaga kerja

\section{Daftar Pustaka}

[1] Crutchfield, N.,\& Roughton, J. (2012). Risk Management Principles, Saf. Cult., pp. 199212, 2014, doi: 10.1016/b978-0-12-396496-0.00010-0.

[2] Kulkarni, K., Goerlandt, F., Li,J., Banda, O. V., \& Kujala, P. (2020). Preventing Shipping Accidents: Past, Present, and Future of Waterway Risk Management with Baltic Sea Focus, Saf. Sci., vol. 129, no. April, p. 104798, doi: 10.1016/j.ssci.2020.104798.

[3] “HIRARC_dan_Risk_Maaping_bab_1_and_3." .

[4] Studi, K., Di, K., Nusantara, $\bar{P}^{-} \mathrm{T}_{.}$, \& Kemilau,I., "Email koresponden: Abasyil@gmail.com,"pp. 91-101.

[5] Waruwu, S., \& Yuamita, F. (2016). Analisis Faktor Kesehatan Dan Keselamatan Kerja (K3) Yang Signifikan Mempengaruhi Kecelakaan Kerja Pada Proyek Pembangunan Apartement Student Castle, Spektrum Ind., vol. 14, no. 1, p. 63, 2016, doi: 
10.12928/si.v14i1.3705.

[6] Putri, D. O., et al. (2018).The Effect of Occupational Health and Safety, Work Environment and Discipline on Employee Performance in a Consumer Goods Company. IOP Conference Series: Materials Science and Engineering Vol.337

[7] Ningsih, S. O. D., \& Hati, S. W. (2019). Analisis Resiko Keselamatan Dan Kesehatan (K3) Dengan Menggunakan Metode Hazard and Operability Study (Hazop) Pada Bagian Hydrotest Manual Di PT. Cladtek Bi Metal Manufacturing. J. Appl. Bus. Adm., vol. 3, no. 1, pp. 29-39, doi: 10.30871/jaba.v3i1.1288.

[8] Christina, W. Y., Ludfi, D.,\& Thoyib, A. (2012). Pengaruh Budaya Keselamatan Dan Kesehatan Kerja ( K3 ) Terhadap Kinerja Proyek Konstruksi. J. Rekayasa Sipil, vol. 6, no. 1, pp. 83-95.

[9] Dallat, C., Salmon, P. M., \& Goode, N. (2019). Risky Systems versus Risky People: To What Extent Do Risk Assessment Methods Consider The Systems Approach To Accident Causation? A Review Of The Literature. Saf. Sci., vol. 119, pp. 266-279, doi: 10.1016/j.ssci.2017.03.012.

[10] Wuryanto, A. W. (2010). Analisis Total Predictive Maintenance Dengan Metode Oee (Overall Equipment Effectiveness) Guna Meningkatkan Performa Pada Mesin Husky (Pt. Xy Gempol) (1). Available online at http://jurnal.yudharta.ac.id/v2/index.php/jkie, no. 2, pp. 81-90.

[11] Afrizal Arif, A. W. (2010). Pengendalian Kualitas Produk Galon Air Mineral 19 L Dengan Pendekatan Six Sigma. Available online at http://jurnal.yudharta.ac.id/v2/index.php/jkie, pp. 81-90.

[12] Ramos, D., Afonso, P., \& Rodrigues, M. A. (2020). Integrated Management Systems As A Key Facilitator Of Occupational Health And Safety Risk Management: A Case Study In A Medium Sized Waste Management Firm. J. Clean. Prod., vol. 262, doi: 10.1016/j.jclepro.2020.121346.

[13] Suyono K. Z., \& Nawawinetu, E. D. (2013). Hubungan Antara Faktor Pembentuk Budaya Keselamatan Kerja Dengan Safety Behaviour di PT DOK dan Perkapalan Surabaya Unit Hull Construction. Indones. J. Occup. Saf. Heal., vol. 2, no. 1, pp. 67-74. 